DOI: http://dx.doi.org/10.18203/2320-1770.ijrcog20170378

\title{
Diagnosis of endometrial pathologies: transvaginal sonography versus hysteroscopy
}

\author{
Berna Aslan Çetin ${ }^{1 *}$, Ayşe Beyaz ${ }^{2}$, Lale S. Türkgeldi ${ }^{1}$, \\ Pınar Yalçin Bahat ${ }^{1}$, Nadiye Köroğlu ${ }^{1}$
}

\begin{abstract}
${ }^{1}$ Department of Gyncecology and Obstetrics, Kanuni Sultan Suleyman Training and Research Hospital, Istanbul, Turkey

${ }^{2}$ Department of Gyncecology and Obstetrics, Istinye Hospital, Istanbul, Turkey
\end{abstract}

Received: 21 November 2016

Accepted: 13 December 2016

\section{*Correspondence:}

Dr. Berna Aslan Çetin,

E-mail: bernaaslan14@hotmail.com

Copyright: (C) the author(s), publisher and licensee Medip Academy. This is an open-access article distributed under the terms of the Creative Commons Attribution Non-Commercial License, which permits unrestricted non-commercial use, distribution, and reproduction in any medium, provided the original work is properly cited.

\begin{abstract}
Background: Abnormal uterine bleeding (AUB) constitutes 69\% of all gynecological complaints in the peri- and postmenopausal age groups. The aim of present study was to compare the accuracy of transvaginal sonography and hysteroscopy in diagnosing intracavitary pathologies in women with abnormal uterine bleeding.

Methods: A total of 303 premenopausal women with abnormal uterine bleeding who admitted to the gynecology outpatient clinic of the Istanbul Kanuni Sultan Suleyman Research and Training Hospital, Istanbul, Turkey, between April 2010 and July 2015, and received hysteroscopy, were evaluated retrospectively. The collected data were assembled from the computerised database. All patients underwent pelvic examination, transvaginal ultrasonography, office hysteroscopy and hystopathologic evaluation. Patients with normal appearing uterine cavities on hysteroscopy additionally underwent full curettage. The pathology reports were considered to be the definitive diagnoses of patients. Transvaginal ultrasonography and office hysteroscopy findings were compared with the pathological reports and the sensitivity, specificity, positive and negative predictive values, accuracy values and likelihood ratios of office hysteroscopy and transvaginal ultrasonography were calculated for the detection of endometrial abnormalities.

Results: Endometrial polyps were the most commonly identified pathology with a rate of $77.56 \%$. The sensitivity, specificity, positive and negative predictive values of transvaginal sonography for diagnosing endometrial pathologies were $77 \%, 32 \%, 75 \%$ and $32 \%$, respectively. The same values for hysteroscopy were $93 \%, 44 \%, 88 \%$ and $48 \%$ respectively. Transvaginal sonography had a sensitivity of $20 \%$ with a specificity of $4 \%$ for submucous myomas. The sensitivity, specificity, positive and negative predictive values of hysteroscopy for submucous myomas when compared to histopathology were $100 \%$ for all.

Conclusions: The diagnostic accuracy of office hysteroscopy for focal lesions such as polyps or submucous myomas is higher than the accuracy of transvaginal ultrasonography. Due to its high diagnostic accuracy, lower complication rate and the ability to obtain direct biopsy specimens while providing simultaneous treatment, we believe that hysteroscopy will retain its place as the gold standard procedure for the investigation of endometrial pathologies.
\end{abstract}

Keywords: Abnormal uterine bleeding, Hysteroscopy, Transvaginal ultrasonography

\section{INTRODUCTION}

Abnormal uterine bleeding (AUB) constitutes $69 \%$ of all gynaecological complaints in the peri- and postmenopausal age groups. ${ }^{1}$ Approximately $30 \%$ of women will experience AUB during their life time.
Although it may be caused by many benign conditions, abnormal uterine bleeding can be a symptom of endometrial cancer in $10 \%$ of peri- and postmenopausal abnormal bleeding cases. ${ }^{2}$ In 2011, the International Federation of Gynecology and Obstetrics (FIGO) menstrual disorders group (FMDG) published PALM- 
COEIN (polyp; adenomyosis; leiomyoma; malignancy and hyperplasia; coagulopathy; ovulatory dysfunction; endometrial; iatrogenic; and not yet classified), a new classification system for abnormal bleeding in the reproductive years. ${ }^{3}$ The biggest challenge in the diagnosis of abnormal uterine bleeding is to distinguish patients with dysfunctional disorders who will require medical treatment from patients with organic lesions who will need surgery.

The most commonly used modalities in the evaluation of AUB are endometrial biopsy, dilatation and curettage (D\&C), transvaginal ultrasonography (TvUSG), saline infusion sonography and hysteroscopy. ${ }^{4}$ In parallel with technological developments TvUSG and office hysteroscopy are the most preferred methods for the diagnosis of abnormal uterine bleeding.

Hysteroscopy is considered to be a highly sensitive method for detecting endometrial pathologies in the current literature. It allows biopsy specimens to be obtained from suspicious endometrial lesions, increasing the rate of correct diagnoses as well as providing treatment during the same session. Due to its high sensitivity rates and no need for subsequent hospitalization, hysteroscopy has begun to take the place of $\mathrm{D} \& \mathrm{C}$ in the diagnosis of abnormal uterine bleeding.

The most common organic causes of abnormal uterine bleeding are endometrial polyps, submucous myomas and endometrial hyperplasias. In the literature incidences of endometrial pathologies that cause AUB differ depending on the selected diagnostic method.

\section{METHODS}

In the present retrospective study we evaluated a total of 315 premenopausal patients with AUB admitted to the Istanbul Kanuni Sultan Suleyman Training and Research Hospital, Obstetrics and Gynecology Department and received hysteroscopy, between April 2010-July 2015. 12 patients were excluded from the study because of missing data. All of 303 patients underwent pelvic examination, transvaginal ultrasonography and hysteroscopy. Present study was approved by the Istanbul Medipol University Ethics Committee.

The age distribution, complaints and pathology results were noted. Systemic diseases, previous history of gynecological interventions, drug use and obstetric history were noted. Exclusion criteria were suspicion of pregnancy, presence of active infection, suspicious cervical lesions and abnormal pap test results. All procedures were done with the same instruments but under the supervision of different experts.

TvUSGs were done with general electric voluson 730 expert ultrasound 5-9 $\mathrm{MHz}$ vaginal probe. Office hysteroscopies were performed with a Richard Wolf
(Germany) hysteroscope with a $2.7 \mathrm{~mm}$ to $7 \mathrm{~mm}$ diameter telescope. The findings were categorized as normal, polyp, submucous myoma, suspicious lesion or endometrial thickness \pm endometrial irregularity. Endometrial thickness was defined as endometrium $>12 \mathrm{~mm}$. Small focal lesions observed during office hysteroscopy were removed with scissors during the procedure. Patients with larger lesions were directed to operative hysteroscopy. Operative hysteroscopies were performed under general anesthesia with a Karl Storz hysteroscope with a $10 \mathrm{~mm}$ outer diameter and $0-30^{\circ}$ angled telescope. Findings were accepted as sufficient and were recorded when the endocervical canal, the entire cavity and both tubal ostiums were observed. The focal lesions detected during operative hysteroscopy were resected, when no lesions were seen full curettage was performed. The exact diagnosis was established with the histological findings.

Histopathological results were classified as normal, polyps, myomas, hyperplasia, polyps+endometrial hyperplasia and other (adenomyosis, endometritis, endocervical polyps, villous structures). The sensitivity and specificity of the hysteroscopy and TvUSG were assessed with final pathology results.

Statistical analysis in this study was performed with the NCSS (Number Cruncher Statistical System) 2007 Statistical Software (Utah, USA) programme. Descriptive statistical methods (mean, standard deviation) as well as sensitivity, specificity, positive predictive value (PPV), negative predictive value (NPV), the accuracy of the test and the likelihood ratio LR (+) of histopathology results with TvUSG and hysteroscopy were calculated. The $\mathrm{p}$ $<0.05$ level were evaluated as significant.

\section{RESULTS}

A total of 315 patients with AUB were examined in the study. 12 patients were excluded from the study because of missing data. 303 patients between the ages of 21 and 51 with AUB and with suspected organic pathologyPALM group- were included into the study. The mean age was $41.42 \pm 8.31$.

According to TvUSG findings the most commonly diagnosed endometrial pathology was endometrial polyps with an incidence of $77.56 \%(n=235)$. According to the hysteroscopy findings, the most common diagnoses were endometrial polyp, submucous myomas and endometrial thickening \pm endometrial irregulatory $77.23 \% \quad(\mathrm{n}=234)$, $9.57 \%(n=29)$ and $5.94 \%(n=18)$, respectively. In $91.42 \%$ of patients, an endometrial pathology was found in the histopathological examination. Endometrial polyps and submucous myomas were the most frequently detected endometrial pathologies with incidences of $74.92 \%$ $(n=227)$ and $7.92 \%(n=24)$, respectively. Endometrial biopsy, TvUSG and hysteroscopy findings are presented in (Table 1). 
Table 1: Distribution of the TvUSG, HS and histopathology results.

\begin{tabular}{|c|c|c|c|}
\hline & Results & n & $\%$ \\
\hline \multirow{5}{*}{$\begin{array}{l}\text { TvUSG (Transvaginal } \\
\text { ultrasonography) }\end{array}$} & Endometrial thickening \pm endometrial irregulatory & 51 & 16.83 \\
\hline & Endometrial polyp & 235 & 77.56 \\
\hline & Submucous myoma & 13 & 4.29 \\
\hline & Normal & 3 & 0.99 \\
\hline & Total & 303 & 100.00 \\
\hline \multirow[t]{6}{*}{ Histeroscopy (HS) } & Endometrial thickening \pm endometrial irregulatory & 18 & 5.94 \\
\hline & Endometrial polyp & 234 & 77.23 \\
\hline & Submucous myoma & 29 & 9.57 \\
\hline & Normal & 21 & 6.93 \\
\hline & Suspicious lesion & 1 & 0.33 \\
\hline & Total & 303 & 100.00 \\
\hline \multirow[t]{7}{*}{ Histopathology result } & Endometrial hyperplasia & 8 & 2.64 \\
\hline & Endometrial polyp & 227 & 74.92 \\
\hline & Submucous myoma & 24 & 7.92 \\
\hline & Normal & 26 & 8.58 \\
\hline & Other & 12 & 3.96 \\
\hline & Endometrial polyp + endometrial hyperplasia & 6 & 1.98 \\
\hline & Total & 303 & 100.00 \\
\hline
\end{tabular}

In present study, TvUSG's sensitivity in detecting endometrial pathology was $77 \%$, specificity $32 \%$, PPV
$75 \%$ and NPV $32 \%$ when compared with histopathologic results. The accuracy and Likelihood Ratio (LR) of TvUSG were $72 \%$ and 0.83 , respectively (Table 2 and 3 ).

Table 2: Sensitivity, Specificity, PPV, NPV, Accuracy and LR of TvUSG for endometrial pathologies.

\begin{tabular}{|l|l|l|l|l|l|l|}
\hline TrUSG & Sensitivity & Specificity & PPV & NPV & Accuracy & LR (+) \\
\hline Endometrial thickening士 endometrial irregulatory & 1.00 & 0.05 & 0.09 & 1.00 & 0.13 & 1.05 \\
\hline Endometrial polyp & 0.84 & 0.05 & 0.90 & 0.03 & 0.77 & 0.88 \\
\hline Submucous myoma & 0.20 & 0.04 & 0.08 & 0.11 & 0.09 & 0.21 \\
\hline TvUSG & 0.77 & 0.32 & 0.75 & 0.32 & 0.72 & 0.83 \\
\hline
\end{tabular}

Table 3: Distribution of TvUSG results according to the histopathology results.

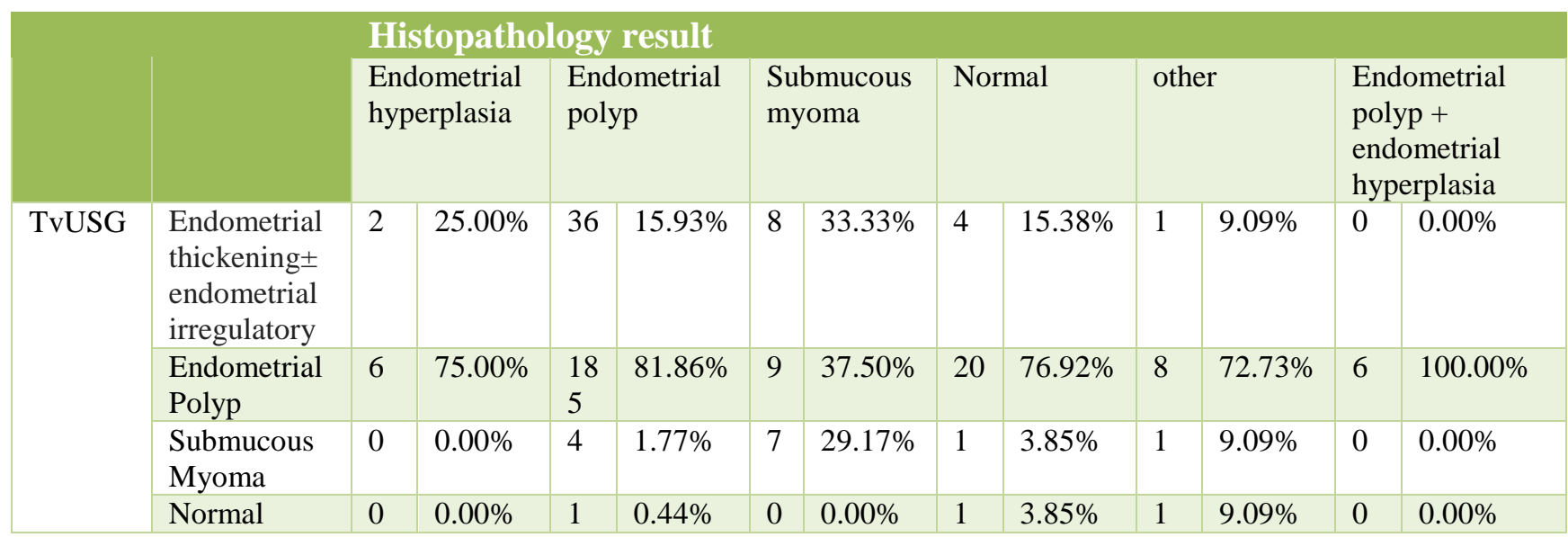

Compared with results of histopathological findings hysteroscopy's sensitivity was $93 \%$, specificity $44 \%$, PPV $88 \%$ and NPV $48 \%$ in the determination of all endometrial pathologies. Accuracy and LR values of hysteroscopy in detecting all endometrial pathologies were $83 \%$ and 1.23 , respectively (Table 4 and 5). 
Table 4: Sensitivity, Specificity, PPV, NPV, Accuracy and LR of HS for endometrial pathologies.

\begin{tabular}{|l|l|l|l|l|l|l|}
\hline HS & Sensitivity & Specificity & PPV & NPV & \multicolumn{3}{|c|}{ Accuracy } & LR (+) \\
\hline $\begin{array}{l}\text { Endometrial thickening } \pm \text { endometrial } \\
\text { irregularity }\end{array}$ & 1.00 & 0.67 & 0.29 & 1.00 & 0.71 & 3.00 \\
\hline Endometrial Polyp & 0.96 & 0.69 & 0.98 & 0.55 & 0.94 & 3.06 \\
\hline Submucous Myoma & 1.00 & 1.00 & 1.00 & 1.00 & 1.00 & - \\
\hline HS & 0.93 & 0.44 & 0.88 & 0.48 & 0.83 & 1.23 \\
\hline
\end{tabular}

Table 5: Distribution of HS results according to the histopathology results.

\begin{tabular}{|c|c|c|c|c|c|c|c|c|c|c|c|c|c|}
\hline \multicolumn{14}{|c|}{ Histopathology result } \\
\hline & & \multicolumn{3}{|c|}{$\begin{array}{l}\text { Endometrial } \\
\text { hyperplasia }\end{array}$} & $\begin{array}{l}\text { Endometrial } \\
\text { polyp }\end{array}$ & \multicolumn{2}{|c|}{$\begin{array}{l}\text { Submucous } \\
\text { myoma }\end{array}$} & \multicolumn{2}{|c|}{ Normal } & \multicolumn{2}{|c|}{ Other } & \multicolumn{2}{|c|}{$\begin{array}{l}\text { Endometrial } \\
\text { polyp + } \\
\text { endometrial } \\
\text { hyperplasia }\end{array}$} \\
\hline \multirow{5}{*}{ HS } & $\begin{array}{l}\text { Endometrial } \\
\text { thickening } \pm \\
\text { endometrial } \\
\text { irregularity }\end{array}$ & 2 & $25.00 \%$ & 10 & $4.41 \%$ & 0 & $0.00 \%$ & 5 & $19.23 \%$ & 1 & $9.09 \%$ & 0 & $0.00 \%$ \\
\hline & $\begin{array}{l}\text { Endometrial } \\
\text { polyp }\end{array}$ & 6 & $75.00 \%$ & 198 & $87.22 \%$ & 6 & $25.00 \%$ & 11 & $42.31 \%$ & 6 & $54.55 \%$ & 6 & $100.00 \%$ \\
\hline & $\begin{array}{l}\text { Submucous } \\
\text { myoma }\end{array}$ & 0 & $0.00 \%$ & 9 & $3.96 \%$ & $\begin{array}{l}1 \\
8\end{array}$ & $75.00 \%$ & 0 & $0.00 \%$ & 2 & $18.18 \%$ & 0 & $0.00 \%$ \\
\hline & Normal & 0 & $0.00 \%$ & 9 & $3.96 \%$ & 0 & $0.00 \%$ & 10 & $38.46 \%$ & 2 & $18.18 \%$ & 0 & $0.00 \%$ \\
\hline & $\begin{array}{l}\text { Suspicious } \\
\text { lesion }\end{array}$ & 0 & $0.00 \%$ & 1 & $0.44 \%$ & 0 & $0.00 \%$ & 0 & $0.00 \%$ & 0 & $0.00 \%$ & 0 & $0.00 \%$ \\
\hline
\end{tabular}

In present study TvUSG's sensitivity of diagnosing submucous myomas was found $20 \%$ and specificity was $4 \%$ compared with endometrial biopsy diagnosis. TvUSG's PPV for submucosal myomas was $8 \%$, NPV was $11 \%$, accuracy was $9 \%$ and LR was 0.21 . TVUSG's sensitivity for diagnosis of endometrial polyps was $84 \%$, specificity was $5 \%$, PPV was $90 \%$, NPV was found to be $3 \%$ compared with endometrial biopsy. Diagnostic accuracy was $77 \%$ and LR (+) was calculated as 0.88 .

Hysteroscopy's sensitivity in the diagnosis of endometrial polyps was $96 \%$, specificity was $69 \%$, PPV was $98 \%$, NPV was calculated as $55 \%$ compared with endometrial biopsy. Hysteroscopy's accuracy in detecting endometrial polyps and LR values were 94\% and 3.06, respectively. In present study, hysteroscopy's sensitivity was $100 \%$, specificity was $100 \%$, PPV was $100 \%$ and NPV was $100 \%$ for submucous myomas.

\section{DISCUSSION}

Endometrial polyps and submucous myomas are the most common organic lesions that cause abnormal uterine bleeding. TvUSG, D\&C and hysteroscopy are used for the diagnosis of the underlying pathology in patients with this condition. In this study we examined the diagnostic accuracy of TvUSG and hysteroscopy for uterine lesions. In a meta-analysis examining 19 prospective studies, TVUSG's sensitivity was found to be between $46 \%$ and
$100 \%$, and its specificity between $12 \%$ and $100 \%$ when compared with histopathological results obtained after hysteroscopy or hysterectomy. ${ }^{5}$ De Vries et al reported TVUSG's sensitivity and specificity as $60 \%$ and $93 \%$, respectively. ${ }^{6}$ Goyal et al found that TVUSG had high sensitivity (95\%), specificity (94\%), PPV (93\%), and NPV $(96 \%)$ in detecting endometrial pathologies. ${ }^{7}$ In present study TVUSG's sensitivity, specificity, PPV and NPV for detecting endometrial pathologies were $77 \%$, $32 \%, 75 \%$ and $32 \%$, respectively. Although the sensitivity, PPV and NPV were similar to previous reports, the specificity of TVUSG in detecting endometrial pathologies was lower than those reported in the literature. We found hysteroscopy's sensitivity as $93 \%$, specificity $44 \%$, PPV $88 \%$ and NPV as $48 \%$ in detecting all endometrial pathologies, in consistence with the literature. Widrich et al found hysteroscopy's sensitivity as 97\%, specificity 93\%, PPV 94\% and NPV as $97 \%$ for all endometrial pathologies, which is higher than present results. ${ }^{8}$ Garuti et al reported hysteroscopy's sensitivity to be $96.5 \%$, specificity $93.6 \%$, and PPV $92.9 \% .{ }^{9}$ D Vitner et al found hysteroscopy's sensitivity and specificity to be $92 \%$ and $67.7 \%$, respectively and TVUSG's sensitivity and specificity to be $44.8 \%$ and $81.8 \%$, respectively, for endometrial polyps. ${ }^{10}$ This is in line with the findings of present study. Several studies have compared the diagnostic values of TVUSG and hysteroscopy for the diagnosis of uterine pathologies. Veena BT et al study showed TvUSG had a low 
sensitivity, but $100 \%$ specificity, and a diagnostic accuracy of $88.3 \%$ for endometrial polyps. ${ }^{11}$

In present study TVUSG's sensitivity was $20 \%$ and specificity was $4 \%$ in detecting submucous myomas. These results are lower than the values reported in the literature. De Varies et al found TVUSG's sensitivity for submucous myomas to be $64 \%$ and specificity $90 \% .{ }^{6}$ In a study published in 2013, D Vitner et al found TVUSG's sensitivity as $85.7 \%$ and specificity as $73.9 \%$ for submucous myomas. ${ }^{10}$ In present study TVUSG's sensitivity and specificity were lower for submucosal myomas than endometrial polyps.

In the present study group hysteroscopy's sensitivity for detecting endometrial polyps was $96 \%$, specificity was $69 \%$, PPV was $98 \%$ and NPV was $55 \%$ compared to the endometrial biopsy results. Birinyi et al found hysteroscopy's sensitivity $87 \%$, specificity $89 \%$, PPV $66 \%$ and NPV 96\%.12 Vercellini et al found hyteroscopy's sensitivity $86 \%$, specificity $94 \%$, PPV $91 \%$ and NPV $90 \%$ for endometrial polyps. ${ }^{13}$ Garuti et al reported hysteroscopy's sensitivity, specificity, PPV and NPV; $95.3 \%, 95.4 \%, 98.9 \%$ and $81.7 \%$, respectively, in detecting endometrial polyps. ${ }^{9}$ Hysteroscopy identifies endometrial polyps effectively.

In present study hysteroscopy's sensitivity was $100 \%$, specificity was $100 \%$, PPV was $100 \%$ and NPV was $100 \%$ for submucous myomas. In a recently published meta-analysis hysteroscopy's sensitivity was reported to be $97 \%$ and specificity $98.9 \%$ for submucous myomas. ${ }^{14}$ Widrich et al found hysteroscopy's sensitivity to be $100 \%$, specificity $96 \%$, PPV $87 \%$ and NPV $100 \%$ for submucous myomas. ${ }^{8}$ Vercellini et al reported hysteroscopy's sensitivity 95\%, specificity $81 \%$, PPV $85 \%$ and NPV $93 \%$ for submucous myomas. ${ }^{13}$

Transvaginal ultrasonography's relative simplicity and availability makes it a very helpful tool for screening, but its relatively modest diagnostic value for most of the uterine pathologies makes interpretation of the findings rather challenging for the physician. Two patients $(0.6 \%)$ who were reported to have normal findings on TvUSG were found to have an organic lesion upon histopathologic examination and 25 patients $(8.3 \%)$ who appeared to have an organic lesion on TvUSG had normal histopathological results. 11 patients $(3.6 \%)$ who were reported to be normal by hysteroscopy were found to have an organic lesion upon histopathological examination and 16 patients $(5.3 \%)$ who were reported to have an organic lesion by hysteroscopy had normal histopathology results.

\section{CONCLUSION}

As a result in present study, hysteroscopy remains the best option for the assessment of the endometrium due to its established accuracy in diagnosis when compared to ultrasonographic imaging modalities. It allows direct visualization of the cavity and sampling for histopathological examination. We have demonstrated that hysteroscopy is the gold standard for detection of endometrial pathologies, but not all pathologies can be detected by hysteroscopy and D\&C should be performed if an organic lesion is suspected.

\section{Funding: No funding sources}

Conflict of interest: None declared

Ethical approval: The study was approved by the Institutional Ethics Committee

\section{REFERENCES}

1. Emanuel MH, Verdel MJC, Stas H. An audit of true prevalence of intrauterinepathology: the hysteroscopical findings controlled for patient selection in 1202 patients with abnormal uterine bleeding. Gynaecol Endosc. 1995;4:237-41.

2. Creasman W.T. Endometrial cancer: incidence, prognostic factors, diagnosis, and treatment. Semin Oncol. 1997,24,S1-140-50.

3. Munro MG, Critchley HO, Broder MS, Fraser IS. FIGO Working Group on Menstrual Disorders. FIGO classification system (PALM-COEIN) for causes of abnormal uterine bleeding in nongravid women of reproductive age. Int J Gynaecol Obstet. 2011;113(1):3-13.

4. Williams CD, and Marshburn PB. A prospective study of transvaginal hydrosonography in the evaluation of abnormal uterine bleeding. Am J Obstet Gynecol. 1998;179:292-8.

5. Farquhar C, Ekeroma A, Furness S, Arroll B. Systematic review of transvaginal ultrasonography, sonohysterography and hysteroscopy for the investigation of abnormal uterine bleeding in premenopausal women. Acta Obstet Gynecol Scand. 2003;82:493-504.

6. de Vries LD, Dijkhuizen FP, Mol BW, Brölmann HA, Moret E, Heintz AP. Comparison of transvaginal sonography, Saline infusion Sonography and Hysteroscopy in premenopausel women with abnormal uterine bleeding. J Clin Ultrasound. 2000;28(5):217-23.

7. Goyal BK, Gaur I, Sharma S, Saha A, Das NK. Transvaginal sonography versus hysteroscopy in evaluation of abnormal uterine bleeding. Med J Armed Forces India. 2015;71(2):120-5.

8. Widrich T, Bradley LD, Mitchinson AR, Collins RL. Comparison of saline infusion sonography with Office hysteroscopy for the evaluation of the endometrium. Am J Obstet Gynecol. 1996;174(4):1327-34.

9. Garuti G, Sambruni I, Colonnelli M, Luerti M. Accuracy of hysteroscopy in predicting histopathology of endometrium in 1500 women. J Am Assoc Gynecol Laparosc. 2001;8(2):207-13.

10. Vitner D, Filmer S, Goldstein I, Khatib N, Weiner Z. A comparison between ultrasonography and hysteroscopy in the diagnosis of uterine pathology. 
Eur J Obstet Gynecol Reprod Biol. 2013;171(1):1435.

11. Veena BT, Shivalingaiah N. Role of transvaginal sonography and diagnostic hysteroscopy in abnormal uterine bleeding. J Clin Diagn Res. 2014;8(12):OC06-8.

12. Birinyi L, Daragó P, Török P, Csiszár P, Major T, Borsos A, Bacskó G. Predictive value of hysteroscopic examination in intrauterine abnormalities. Eur J Obstet Gynecol Reprod Biol. 2004;115(1):75-9.

13. Vercellini P, Cortesi I, Oldani S, Moschetta M, De Giorgi O, Crosignani PG. The role of transvaginal ultrasonography and outpatient diagnostic hysteroscopy in the evaluation of patients with menorrhagia. Hum Reprod. 1997;12:1768-71.

14. Mahmud A, Smith P, Clark J. The role of hysteroscopy in diagnosis of menstrual disorders. Best Pract Res Clin Obstet Gynaecol. 2015;29(7):898-9.

Cite this article as: Çetin BA, Beyaz A, Türkgeldi LS, Bahat PY, Köroğlu N. Diagnosis of endometrial pathologies: transvaginal sonography versus hysteroscopy. Int J Reprod Contracept Obstet Gynecol. 2017;6:544-9. 